\title{
Expectations and Realities of Knowledge Management: Experiences from Higher Education in Developing Countries
}

\author{
- Krishna Prasad Paudel \\ PhD Scholar, Kathmandu University
}

\begin{abstract}
The aim of this paper is to view the theoretical and practical aspects of knowledge management in the higher education of developing countries of Asia and Africa. It also emphasizes the usage and importance of Knowledge Management (KM) in developing countries. This paper argues that the use of $K M$ is growing day by day in higher education institution after the development of information technology (IT), and information and communication technology (ICT). KM is highlighted in the developing countries along with the enablers of KM such as technology, leadership, culture and environment. Consequently, development of KM is not going ahead as intended in such countries. The aim of this paper is to explore the status and impact of KM in higher education institutions (HEIs) of developing countries. In this era, the usage of KM is increasing day by day in business sectors and educational institutions as well. This paper aims to elaborate the expectations of KM in higher education institutes of developing countries.
\end{abstract}

Keywords/terms: Higher educational institution, knowledge economy, knowledge management, teaching, learning

\section{Introduction}

Knowledge is important to both public and private institutions, particularly in learning institutions which include higher education institutions such as colleges and universities. The development of creation and accessibility of new and existing knowledge presents abundant opportunities as well as remarkable challenges to organizational competition in global arena. In the last two decades, there has been a growing interest in researches on the impact of knowledge management (KM) in organizations. However, most of the research projects in this connection have been considered in business industry compared to educational institutions (Ramachandran, Chong and Ismail, 
2009). The current state of KM in higher education (HE) sector is unclear (Sunalai and Beyerlein, 2015), when in fact educational institutions are equally challenged to keep pace with the changes in global business environment and technological advancement in today's knowledge-based economy.

The concept of knowledge started with the words of Jafari who stated the word "knowledge" as an extensive usage and said that there are many definitions of it with diverse background, and everyone has different understandings of knowledge in the field of KM (Jafari and others, 2007). In the line of Redman and Wilkinson (2009), KM is the attempt made by an organization to explicitly manage and control knowledge. More than this, $\mathrm{KM}$ is an integrated management and sharing of knowledge that can enable an organization to achieve its objectives (Mathew, 2010). It is appropriate to put the nine-stage approach of $\mathrm{KM}$ for an organizational context; the approach includes these stages: convert data into knowledge, identify and evaluate the knowledge, capture and preserve knowledge, organize knowledge, use knowledge, combine knowledge, create knowledge, learn about knowledge, distribute and sell knowledge to achieve organizational goal. (Liebowitz and Suen, 2000)

Different authors have explained the term 'knowledge' differently. Accordingly, it has been conceived in terms of information, acquaintance with facts, truth, belief, data that carry some meaning to be information (Lundvall, 2013); or skills gained through experience called 'know how' knowledge (Man, 2012). Knowledge is a source of production through the human activities that can contribute to this socially structured world (Almudallal and others, 2015). In educational context, $\mathrm{KM}$ is explained as a set of practices that helps an institution to improve their teaching, research and administrative roles, and encourages the use and sharing of data and information in decision making (Petrides and Nodine, 2003). So, knowledge helps to modify the behavior of the faculty members and students of HEIs through the acceptance of tacit knowledge gaining by research activities in the university.

$\mathrm{KM}$ was initially defined as the process of applying a systematic approach to capture, structure, manage and disseminate knowledge throughout an organization in order to work faster, and reuse best practices (Nonaka and Takeuchi, 1995). In this regard, knowledge management helps to collect the information about various facts and to gain the skills and experiences of faculty member of HEI to enhance academic activities. Knowledge can be achieved through academic activities within colleges and universities. When people gain knowledge, they modify their behavior in accordance with the 
situation and environment. Knowledge management is concerned with using the knowledge for the betterment of any organization. In educational institutions, knowledge management helps to manage the academic activities which can speed up the academic activities of the students and faculty members. Knowledge management is a collaborative and integrated approach to creation, capturing, organization, access and use of an enterprise's intellectual assets. In this regard, Wiig (1993) considers knowledge management in organizations from three perspectives; business perspective, management perspective, and hands-on perspective.

There are two types of knowledge involved in higher education setting: academic knowledge and organizational knowledge. Academic knowledge is the primary purpose of universities and colleges, whereas organizational knowledge refers to knowledge of the overall business activities of an institution that includes its strengths and weaknesses, the community it serves, market it targets, and the critical factors for organizational success (Coukos, 2003). Knowledge management is being used these days in the university to enhance educational activities, research activities, innovation and learning process (Dhamdhere, 2015). Higher educational organizations can integrate their knowledge by research activities to meet institution's goal or target (Bhusry and Ranjan, 2011). Now knowledge has become a main production factor and the final production of any higher education institution (Nayak and Barboza, 2014). And it is important for the management of organizational information and knowledge by applying skills, experiences, innovation and intelligence (Bhusry and Ranjan, 2011). Knowledge is really a great access. The Sanskrit saying states knowledge as the greatest wealth (Vidhya Dhanam Sarba Dhanam Pradham). KM practices involve an organization's activities that manage a flow of knowledge throughout an organization (Heisig, 2009).

Most of the KM researches mention organizational culture, information technology, leadership, KM strategy and motivation as the influencing factors or KM enablers for the success of KM in organization. KM enablers are the driving forces in carrying out KM that do not only generate the knowledge in the organizations by stimulating the creation of knowledge, but they also motivate the group members to share their knowledge and experiences with one another, allowing organizational knowledge to grow concurrently and systematically. Anantatmula and Kanungo (2011) conducted a research among university faculties and staffs using interpretive structure modeling to identify the underlying relations among the set of 
enablers and barriers for successful implementation of KM initiatives. The research results showed that top management involvement, KM leadership and the culture of the organization are the main driving factors based on which one can build a successful KM effort. With the involvement of top management, KM initiatives will gain support and active participation of the senior executives of the organization.

Sujatha (2007) explored critical success factors for implementation KM. The study highlighted barriers and challenges that face KM efforts and showed that organizations have knowledge distributed across people, technologies, and organizational practices, and acquire new knowledge that will enable them to stay competitive in the market place.

In order to build a successful KM initiative, organizations need to secure the involvement of top level management at first. Additionally, selection of a competent and committed leader is important for the initiative because the leader plays a critical role in securing funds and building technology infrastructure to accomplish KM goals and objectives.

\section{$\mathrm{KM}$ in the universities of developing countries}

The literature review was based on the practices followed in the universities of lower middle-income countries from Asia and Africa, that are practicing KM. Based on the report of Fantom (2016), least developed countries, particularly three countries from Asia, namely India, Pakistan and Bangladesh and two countries from Africa, namely Kenya and Nigeria, were randomly sampled for this literature review. HEIs in these developing countries are trying to make policies and encouraging the stakeholders of the institutions to take active part for minimizing the barriers and promoting successful practices of KM (Islam and others, 2014). Knowledge management practices have great relevance and application to the educational institutions. Application of knowledge management practices in higher education can lead to better decision-making capabilities, reduced time in "product" development cycle; curriculum development and research, improved academic and administrative services, and reduced costs (Kidwell and others, 2000). Mikulecky and Mikulecka (1999) addressed the role of $\mathrm{KM}$ in universities as the component of sustainable environment in terms of teaching and learning process, research process, curriculum development, and administrative process. I would like to put the major ideas of some scholars for knowledge management.

In educational context, business perspective is followed to formulate and 
develop strategies and policies to develop market share of any institution, while management perspective is followed to organize and manage knowledge-based activities to achieve organizational strategies and objectives. Likewise, hands on perspective is used to apply the expertise of individuals to enhance organizational value.

In any country, higher educational institutions play significant roles to apply knowledge practices to support every part of their mission (Kidwell and others, 2000). It is found that two important roles have been played by higher educational institutions of developing countries viz. creating knowledge and diffusing knowledge. Higher education institutions of the developing countries have three major objectives. The first is concerned with developing tasks for better quality and effectiveness. The second related to developing human resources in all operating levels; and the third is concerned with developing knowledge bases of organizations or sectors towards enhanced knowledge investment or wisdom investment of the organizations (Redman and Wilkinson, 2009). Apart from such objectives, knowledge management also provides solutions to the problems that are relevant for sustainable teaching-learning processes in higher education (Mathew, 2010). Knowledge management also provides intellectual capacities and cognitive abilities of the workers of the institutions of higher education and scientific research at all levels. Moreover, knowledge management also enables the higher educational institutions to be ready to face them and avail the opportunity to increase and develop the best practices and approaches of academic activities.

Developing countries are in the trend of using $\mathrm{KM}$ in their educational institutions widely at present. The study of Abass and others (2011) in a recent descriptive survey revealed the acceptability of KM practices in public sector of Pakistan. They surveyed two educational institutes secondary education board and a higher education institute. During their research, they found positive perceptions of employees towards organizational culture, KM practices, and organizational performance. Their descriptive results showed positive trend of each of the variables. According to the employees working in different organizations under government sector of Pakistan, the culture of their respective organizations encourages and provides opportunity for the communication of ideas and knowledge. Moreover, performance of the surveyed organizations was satisfactory in terms of employees' satisfaction, their retention, operating costs, etc. Such 
studies are the steps for the materialization of knowledge management. Still there is less periodization of ICT in such countries.

Similarly, Yusoff and others (2012) explored the relationship of KM implementation and KM enabler among members in a community college of Malaysia. The researchers identified the possibility of developing a socioeconomic center at the community colleges with strong links to the government, coordinated by a management, which actively supports the technology and knowledge transfer and provides communities with facilities and services. This attracts mainly the local communities that expect benefits and synergies from these colleges. The researchers believed that their research had just opened a space to improve KM. In the future, researchers would recognize the main activities in community college that can be defined clearly as part of $\mathrm{KM}$; and then they would further propose a framework for those activities that can be used practically by the staff of community college.

Similarly, Chumjit (2012) explored the application of knowledge management (KM) in the higher education institutions of Thailand. Based on a qualitative research design, Chumjit studied four autonomous universities of Thailand and reported that those universities tried to create new knowledge (both tacit and explicit). New methods for improving teaching, research, administration, and strategic planning have been created and KM has successfully been applied within various sections and departments. Feliciano (2007) conducted a study, which showed that there were many empowerment factors that made KM more effective, and encouraged the knowledge workers towards greater interaction with the knowledge base, such as the criteria for transparency, adaptation and reliability.

The very objective of Indian HEI is to integrate the knowledge produced at all levels and using it towards the institute's goals and targets (Bhusry and Ranjan, 2011). I understand that knowledge is created by any academic institution during their academic and administrative process. They are in the phase of developing their efficiency to tackle problems from cross functional, cross organizational, ethical and cultural perspectives. Such efficiencies can be developed from the various ways like academic libraries. The academic libraries in Indian HEI support the mission of their parent institutions to generate knowledge, equip people with knowledge in order to serve the society and advance the wellbeing of mankind (Aswath and Gupta, 2009). 
A case study report of Nath and Tanjeen (2016) stated that the organizations in Bangaladesh that want to endure in unpredictable markets should rapidly adapt to the new dynamics of KM. Knowledge is considered as strategic company's resource, the source of competitive advantage and business success in the 21 st century. They further suggested the organizations to implement the KM practice within the organization. For this it was essential that the KM organizational strategy was to be well defined, and it had to address issues such as organization's goals and competitive advantage, access tacit knowledge, promote creativity, capture new learning, and build a supportive culture. Mostofa and Islam (2015) also conducted a case study to find the challenges and opportunities of knowledge management in university library in the University of Dhaka. They recommended patronization as an essential part for the development of any organization. They suggested the organizations to take KM seriously and allocate sufficient financial resources in order to provide needed KM infrastructures. Apart from this, providing training, incentives and infrastructure were other major things recommended by them.

Like in many other countries, the development of higher educational institutions in Pakistan was also started after the end of colonization. Mikulecky, Lodhi, and Mastorakis' (2009) case study of knowledge management in educational institutions reported that the role of universities particularly in Pakistan should be to use knowledge management principles and approaches to improve their standards and also act as knowledge repositories for corporate. By doing so, universities can improve their performance at national as well as international level. They suggested that just like the business economy where the goal is how to maximize the profit and minimize the input cost, the goal of knowledge economy is to push employees towards greater efficiency and productivity by making more efficient use of knowledge.

In the Nigerian context, only a few studies have examined the knowledge management processes in place at universities. Uchendu and others (2012) examined knowledge management and university lecturers' job performance in Cross River State, Nigeria. The above-mentioned researchers studied knowledge management from the angle of knowledge sharing and knowledge mapping which, they suggest, are its two most crucial components. They found a significant relationship between knowledge sharing, knowledge mapping, and lecturers' job performance. Ohiorenoya and Eboreime (2014) surveyed knowledge management practices and performance in some Nigerian 
universities. These researchers measured knowledge management via six components: creation, capturing, organization, storage, dissemination, and application. They found a high positive correlation between knowledge management and performance. An integrated knowledge management model developed by Evans and others (2005) have focused on knowledge management practices in the HEI of Nigeria. They pointed out the need for developing an integrated knowledge model by defining the stages in the context of the operations of a university. The researchers also mentioned that universities in Nigeria, as elsewhere in Africa, face challenges that prevent them from achieving their goals and objectives.

Bray and Konsynki (2015) in the study of knowledge management and its impact on organizational performance emphasized the importance of IT knowledge diffusion in the entire organization of Kenya. Kimile's (2011) study findings established that $\mathrm{KM}$ in university lacks integrated knowledge management strategies that enable a knowledge sharing culture, and that the available technology did not adequately address Knowledge Management, so the top management needs to ensure knowledge creation as the top priority, and knowledge workers should be held accountable for their knowledge exchange efforts (Muhoya, 2016). The cases of the different countries of the Asia and Africa shows that KM is being practiced more in the different institutions such as banking, industries and other institutions compared to academic institutions.

\section{Challenges of knowledge management}

The higher education institutions can be considered as knowledge creating organizations. They are developing and sharing successful practices across colleges and departments as well as evaluating and upgrading best practices to reach a setup of knowledge domains (Shermon, 2002). Any higher education institution needs knowledge strategies, polices, and tools to manage their knowledge assets as corporate assets (Chaudhary, 2005). The success of HEI throughout the US is characterized by higher education funding, increased interest in information-sharing practices, greater accountability, and increased information needs of teachers, faculty, staff, and administrators (Petrides and Nodine, 2003). They are often found to have been forced to operate in a much more business-like competitive environment. Therefore, it is very essential to analyze the factors related to knowledge management in a broader sense that requires strategic vision. Organizations create and maximize value whenever they can make sense of the environmental opportunities in which they operate, exploit the embodied 
knowledge at work to meet their strategic goals. It is thus important for any educational system to readdress its strategy content and the KM agenda at the highest strategic levels of an organization (Lelic, 2002).

According to Agarwal and others (2012), a key challenge for the educational administrator in the future will be cultivating "commitment" from knowledge workers to the institutional vision. Self-leadership and selfregulation will have to be practiced so that dynamic change in the environment can be tackled, also the future success of any institution will depend ultimately on self-imposed controls. Therefore, knowledge management is very complex issue for top management to take a decision. It should be addressed deeply from several dimensions such as cultural, technical and human, so that knowledge, experiences and practices can be formalized and applied to make the educational system more innovative, responsive, proactive and knowledge oriented. Thus, collaboration and sharing of knowledge as well as the adequacy of knowledge management infrastructure pose different challenges to different universities. Investment on research and development ( $\mathrm{R}$ and $\mathrm{D}$ ) and leadership commitment to $\mathrm{R}$ and $\mathrm{D}$ are different across organizations. In this scenario, many of the universities in the developing countries like Nigeria have not cultivated the culture of entering into strategic alliances (John, 2015).

KM was effective in university towards achieving innovative objective. In the era of knowledge economy, research activities in universities have gained considerable importance (Flagg and others, 2011) and it is impacted by the leadership and cultural factors of KM enablers. It is found that successful KM practices in HEIs can result in the development of sustainable competitive advantage in market (Madan and Khanka, 2010). Likewise, the usage of KM focuses on educational context, whereby faculty members are fully aware of knowledge sharing, but they were mainly focused on teaching activities and sharing of learning resources (Shahzadi and others, 2015; Islam et al., 2013). This shows that there are challenges in HEIs to implement KM for enhancing the capacity of both academic and administrative staffs.

\section{Conclusion}

Research on the application of KM practices is still in its early stages in the education sector. Creation and maintenance of relevant knowledge repositories, improving knowledge access and environment, and valuing knowledge can benefit higher education institutions. Knowledge 
management is highly prioritized in any higher education institution of developing countries and knowledge intensive organizations - i.e. educational institutions - are using this concept to transfer the knowledge of faculty to the students by using various sorts of technology such as, internet, intranet, e-portal, e-mail, blogs, etc. As the top performers in this era of information technology and communication, universities should accept, adopt and consistently foster their knowledge management practices.

The knowledge management practices adopted by the HEIs of Asian countries play a significant role for shaping the overall development along with the future planning of countries. Likewise, KM in the African countries is being practiced to enhance the academic excellence of students as well as faculty members. Universities have to provide a platform for knowledge management practices by developing the culture and motivating the human element. Once the platform is there, knowledge acquisition, storage and application become inevitable. In the entire process, it should not be forgotten that technology leads the way towards achieving higher performance in the utilization of knowledge management in practices. Utilization of the internet is a must for the dissemination of knowledge. Technology makes things easier and becomes helpful both for the creation and utilization of knowledge management in academic institutions.

\section{References}

Abass Fakhar, Hayat Mazhar, Shahzad Aamir, and Riaz Adnan. (2011). Analysis of knowledge management in the public sector of Pakistan. European Journal of Social Sciences, 19 (4), pp. 471-478.

Agarwal Parul, Kiran, Ravi, and Verma, Anil Kumar. (2012). Knowledge sharing for stimulating learning environment in institutions of higher technical education. African Journal of Business Management, 6(16), pp. 5533-5542.

Almudallal, Abdullah Waleed, Norhani Bakri, Syaharizatul Noorizwan Muktar, and Majed M. El-Farra. (2016). Implementing knowledge management in the palestinian public sector institutions: Empirical study on the presidency of the Palestinian government. International Review of Management and Marketing, 6(4), pp. 101-107.

Anantatmula, Vittal S., and Shivraj Kanungo. (2011). Strategies for Successful Implementation of KM in a University Setting. In Strategies for Knowledge Management Success: Exploring Organizational 
Efficacy. pp. 262-276. IGI Global.

Aswath, Lal, and Gupta, Shanker (2009). Knowledge management tools and academic library services. In International Conference on Academic Libraries, Vision and Roles of the Future Academic Libraries, New Delhi, India, pp. 05-08.

Bhusry, Mamta and Ranjan, Jayanti, Ranjan (2011). Implementing knowledge management in higher educational institutions in India: A conceptual framework. International Journal of Computer Applications, 29(1), pp. 34-46.

Bray, David A., and Konsynski, Benn. (2015). Improved organizational performance by knowledge management: The influence of employee perceptions and variances in distributed e-government and e-business organizations. Retrieved from https://papers.ssrn.com/sol3/papers. cfm?abstract_id=962279.

Chaudhary, Abhay Shankar. (2005). Knowledge sharing practice in Asia institutions: A multi- cultural perspective from Singapore. World Library an Information Congress: 71th IFLA General Conference and Council, pp. 14-18 August 2005, Oslo, Norway.

Chumjit, Surat. (2012). Knowledge management in higher education in Thailand. ProQuest, UMI Dissertations Publishing.

Evans, Max; Dalkir, Kimiz; and Bidian, Catalin (2014). A holistic view of the knowledge life cycle: The knowledge management cycle (KMC) model. The Electronic Journal of Knowledge Management, 12(2), pp. $148-160$.

Fanton, Neil. (2016). The World Bank's classification of countries by income.

Feliciano, Joe. L. (2007). The success criteria for implementing knowledge management systems in an organization. New York, NY: Pace University.

Flagg, Donald., Gilley, Otis.W., and Park, Jung. Chul. (2011). Job market signaling: What drives the productivity of finance PhDs? Financial Management, 40(2), pp. 483-513.

Heisig, Peter. (2009). Harmonisation of knowledge management: Comparing $160 \mathrm{KM}$ frameworks around the globe. Journal of Knowledge Management, 13(4), pp. 4-31. 
Islam, M. A., Ikeda, M., and Islam, M. M. (2013). Knowledge sharing behaviour influences: A study of Information Science and Library Management faculties in Bangladesh. IFLA Journal, 39(3), pp. 221-234.

Islam, Md. Anwarul, Agarwal, Naresh Kumar., and Ikeda, Mitsuru. (2014). Knowledge sharing amongst information professionals in Bangladesh: A quantitative analysis. BOBCATSSS 2014 Proceedings, 1(1), pp. 224-231.

Jafari, Mostafa; Akhavan, Peyman; Akhavan, Nour, Jalal Rezaee; Nour, and Fesharaki, Mehdi N. Fesharaki. (2007). Knowledge management in Iran aerospace industries: A study on critical factors. Aircraft Engineering and Aerospace Technology, 79(4), pp. 375-389.

John, Omogeafe, A. (2015). Labour unions and conflict management in Nigeria: A case study of academic staff union of Nigerian universities (ASUU). World Journal of Management and Behavioural Studies, 3(1), pp. 30-35.

Kidwell, Jillinda J., Karen Vander Vander-Linde, and Sandra L. Johnson. (2000). Applying corporate knowledge management practices in higher education. Educause Quarterly, 23(4), pp. 28-33.

Kimile, Nancy M. (2011). Knowledge management practices at Moi University Eldoret, Kenya, Eldoret: Moi University.

Lelic, S. (2002). "The Knowledge: Thomas A. Stewart." Knowledge Magazine.

Liebowitz, Jay; and Suen, Ching Y. Suen. (2000). Developing knowledge management metrics for measuring intellectual capital. Journal of Intellectual Capital, 1(1), pp. 54-67.

Madan, Pankaj, and Khanka, Sheetal. (2010). Contribution of knowledge management practices in creating sustainable competitive advantage for business schools in India. Journal of Information and Knowledge Management, 9(4), pp. 387-397.

Man, Li. (2012). Knowledge Management, Sharing and Creation in Developing Countries' Banking Industries. Advanced in Network and Communications. doi: 10.4156/anc.vol1.issue1.2

Mathew, V. (2010). Knowledge management in higher education: Implementation agenda in distance learning (pp. 155-158). Fourth International Conference on Distance Learning and Education. 
Mikulecky, Peter, and Mikulecka, Jaroslava. (1999). Active tools for better knowledge dissemination. Washington, DC: ASIS.

Mikulecky, Peter, Lodhi, Mohammad Saeed, and Mastorakis, N. E. (2009, November). Knowledge management at educational institutions: Case of Pakistan. In 10th proceedings of the WSEAS Int. Conference on mathematics and computers in business and economics, pp. 7-9.

Mostofa, Sk Mamun, and Mezbah-ul-Islam, Mezbah. (2015). Challenges and opportunities of knowledge management in university library: A case study of Dhaka university library in Bangladesh. Journal of Information Science Theory and Practice, 3(4), pp. 49-61.

Mostofa, Sk-Mamun, and Muhammad Mezbah-ul-Islam. (2015). Challenges and opportunities of knowledge management in university library: A case Study of Dhaka University Library in Bangladesh. Journal of Information Science Theory and Practice, 3(4), pp. 49-61.

Muhoya, NANCY MWERU, (2016). The influence of knowledge management practices on performance of selected global audit firms in Kenya (Master's thesis). School of Business, University of Nairobi, Kenya.

Nath, Tanuza, and Tanjeen, Ethica. (2016). A Conceptual Skeleton.

Nonaka, Ikujiro, and Takeuchi, Hirotaka. (1995). The knowledge, creating company: How Japanese companies create and dynamics of innovation? New York, NY: Oxford University Press.

Ohiorenoya, John Omogeafe, and Eboreime, Ohimai Friday. (2014). Knowledge management practices and performance in Nigerian universities. European Scientific Journal, 10(16), pp. 400-416.

Petrides, L. A., and Nodine, T. R. (2003). Knowledge management in education: Defining the landscape. Half Moon Bay, CA: Institute for the Study of Knowledge Management in Education.

Ramachandran, Devi Sharimllah, Chong, Chong Siong, and Ismail, Hishamuddin. (2009). The practice of knowledge management processes: A comparative study of public and private higher education institutions in Malaysia. The Journal of information and knowledge management systems, 39(3), pp. 203-222.

Redman, Tom, and Wilkinson, Adrian. (2009). Contemporary human resource management: Text and cases (3rd ed.). Harlow: Prentice Hall. 
Shahzadi, Irram, Hameed, Raja Mazhar, and Kashif, Abdul Rauf. (2015). Individual motivational factors of optimistic knowledge sharing behavior among University academia. The Business and Management Review, 6(1), pp. 134-145.

Shermon, Gansh, (2002). Knowledge management as key to strategy. Indian Management, 41(7), pp. 74-76.

Sunalai, Suravee, and Beyerlein, Michael. (2015). Exploring knowledge management in higher education institutions: Processes, influences, and outcomes. Academy of Educational Leadership Journal, 19(3), pp. 289308.

Uchendu, C., Osim, R., and Akuegwu, B. (2012). Knowledge management and university lecturers' job performance in Cross River State, Nigeria. Journal of Education and Practice, 3(15), pp. 1-6.

Wiig, Karl M. (1993). Knowledge management foundations: Thinking about thinking - How people and organizations create, represent and use knowledge. Arlington: Schema Press.

Yusoff, Mohamad, Mahmood, Ahmad, and Jaafar, Jaafar. (2012). A study of $\mathrm{KM}$ process and $\mathrm{KM}$ enabler in a Malaysian community college. Journal of Knowledge Management Practice, 13(1). Retrieved from http://www.tlainc.com/articl297.htm. 